\title{
PERCEPÇÕES DE PROFESSORES SOBRE O ENSINO DA LÍNGUA INGLESA EM UMA CIDADE DE PEQUENO PORTE DO ESTADO DE SANTA CATARINA
}

\author{
CREMILDA MARTINS FUERST \\ Rosana Mara KoERner \\ Universidade da Região de Joinville (UNIVILLE), Joinville, Santa Catarina, Brasil
}

\begin{abstract}
Resumo: Neste artigo serão apresentadas as percepções de professores sobre o ensino da Língua Inglesa em relação à formação docente, às condições de trabalho e aos recursos pedagógicos. Trata-se de uma pesquisa qualitativa. Na coleta dos dados, utilizamos questionários respondidos por professores de inglês da cidade e entrevistas com quatro professoras. A partir da análise, foi possível observar a ausência de formações continuadas e, por isso, as professoras buscam alternativas para se manterem atualizadas. Há, também, a percepção do pouco tempo para o desenvolvimento das habilidades linguísticas, ainda que haja recursos pedagógicos disponíveis. Com relação ao uso dos gêneros textuais, nota-se pouca variação, ficando entre a letra de música, o diálogo e os jogos, indicando uma tendência ao lúdico.
\end{abstract}

Palavras-chave: Professores de Língua Inglesa. Formação Docente. Condições de Trabalho. Uso de Gêneros Textuais.

\section{INTRODUÇÃO}

Em um mundo em crescente processo de globalização, é inegável o papel desempenhado pela Língua Inglesa (LI) como o principal veículo de comunicação em meio à profusão de línguas. Assim, para além dos aspectos culturais envolvidos na aquisição de uma língua estrangeira, aprender a Língua Inglesa se constitui, hoje, como uma prerrogativa para a ampliação das possibilidades de inserção no mundo do trabalho. Nesse cenário, à Educação Básica foi dada a incumbência do ensino da Língua Inglesa, com o intuito de possibilitar sua aprendizagem por meio de práticas linguísticas cotidianas e discursivas, e da reflexão sobre elas. Na LDB de 1996 consta que "é obrigatório o início do ensino da LE a partir do $6^{\circ}$ ano" (BRASIL, 1996, p.20), alterado para LI na Lei no 13.415/2017.

A partir da obrigatoriedade do ensino da LI nas escolas de Educação Básica do país, os estados e municípios tiveram que se organizar para a oferta da língua em suas escolas, o que implica pensar no seu corpo docente e sua respectiva formação, nas condições de trabalho e nos recursos disponibilizados para isso. No presente estudo, serão trazidas informações sobre como se deu esta organização em um município de pequeno porte. Também foi dada voz aos professores de Língua Inglesa para que indicassem as suas percepções sobre o ensino desta língua, as condições de trabalho e sobre o seu processo de formação continuada. 
Com o objetivo de verificar quais são essas percepções, aqui serão discutidos aspectos relacionados ao ensino da LI, como: a formação docente, as condições de trabalhos e os recursos disponíveis. Com uma perspectiva qualitativa, os dados foram obtidos por meio de questionários e entrevistas feitos com professoras de LI de uma cidade de pequeno porte no estado de Santa Catarina. A questão que norteia a discussão dos dados aqui apresentados foi assim delineada: Quais as percepções de professores sobre o ensino da LI em uma cidade de pequeno porte? Aqui está sendo omitido o nome do município, que tem cerca de 41.380 habitantes. Nos Apoiamos nos estudos de: Carvalho (1999), Tardif e Lessar (2005) e Vasconcelos (2009).

O artigo é iniciado com as Considerações iniciais, seção na qual são apresentados os pressupostos teóricos que orientaram a análise, além dos documentos que regulam o ensino da Língua Inglesa no município em questão. Seguida da Metodologia, quando são apresentados os procedimentos de geração de dados. Os dados são discutidos na seção intitulada Os professores de Língua Inglesa: Investimento na própria formação e condições de trabalho, e nela são apresentadas as principais conclusões obtidas com o estudo e novos encaminhamentos de pesquisa. A discussão que aqui se apresenta é parte de uma dissertação de mestrado em um programa de Educação de uma universidade comunitária de Santa Catarina.

\section{CONSIDERAÇÕES INICIAIS}

O percurso do ensino da LI no Brasil está estreitamente relacionado ao percurso do ensino da Língua Estrangeira (doravante LE), que começa com a história do país, em 1500, quando os colonizadores aqui chegaram. A Língua Portuguesa passou a ser ensinada aos índios informalmente pelos jesuítas, enquanto estes os catequizavam. Nesse sentido, a LP passou a ser considerada a primeira LE falada em terras brasileiras. Entretanto, Garcia (2007) relata que em 1750, por questões econômicas, administrativas e educacionais, o primeiro ministro nomeado por Dom José I, rei de Portugal (17501777), Marquês de Pombal, expulsou os jesuítas do Brasil e proibiu o ensino e o uso da língua indígena, tornando o português a língua oficial. Esse ministro, de forma a defender o estado absolutista português, reorganizou o estado, protegeu grandes empresários, criou as companhias de comércio, além de combater tanto os nobres quanto o clero.

A língua francesa e a língua inglesa foram incluídas oficialmente no currículo quando a família real chegou ao Brasil em 1808, pois "[...] teriam como função possibilitar o falar e o escrever nos respectivos idiomas, a fim de conhecer 'as belezas e elegância' dessas línguas, além de utilizar os autores clássicos do século XVI" (BRASIL, 1851, p. 29). A vinda da corte de D. João Vl, em situação de fuga de Portugal, foi feita por meio de escolta de navios ingleses, os quais com isso lograram o direito de fazer negócios por aqui.

Lá se foram mais de dois séculos e a língua inglesa permanece com o mesmo valor de outrora, não só comercial como social e de interação, pois é a língua mais falada no mundo, com a qual as pessoas de todos os continentes se comunicam. 
FUERST, C. M.; KOERNER, R. M.

Os ingleses trouxeram o telégrafo, o trem de ferro e a iluminação a gás e, para implantar tudo isso nas terras brasileiras, precisavam da mão de obra de engenheiros e técnicos, mas os candidatos a estes postos de trabalho precisavam falar inglês, pois os treinamentos para poderem desempenhar suas funções seriam dados nessa língua.

Diante disso, viu-se a necessidade de oferecer o ensino da LI de forma prática e eficiente para sanar esse obstáculo: "É muito provável que os primeiros professores de inglês tenham surgido nesse momento" (CHAVES, 2004, p. 5). Porém, segundo Chagas (1976, p.105), somente em 1837, com a criação do Colégio Pedro II, o ensino de LI teve seu início oficial. Em 1930, com a criação do Ministério da Educação e Saúde Pública, um dos primeiros atos do governo de Getúlio Vargas foi a destinação de 17 horas semanais ao ensino de francês e inglês, da primeira à quarta série (PAIVA, 2003). A LDB nº 4.024/61 retirou a obrigatoriedade do ensino de línguas no colegial, deixando ao Estado a decisão de incluir ou não a disciplina no currículo (BRASIL, 1961).

Em 1976, o Ministério da Educação, através da Resolução n 58/76, promoveu parcialmente o resgate do ensino de LE nas escolas e a obrigatoriedade do ensino foi decretada em 1977, mas somente para o colegial, não para o ginásio. Em 1971, o ginásio foi fundido com o ensino primário, dando origem ao ensino de $1^{\circ} \mathrm{grau}$. Na sequência da Lei de Diretrizes e Bases da Educação de 1996, o ensino de $1^{\circ}$ grau foi substituído pelo ensino fundamental. A LDB de 1996 torna "[...] obrigatório o início do ensino da LE a partir do $6^{\circ}$ ano" (BRASIL, 1996, p. 20), alterado para LI na Lei $n^{\circ}$ 13.415/2017.

Conforme a Proposta Curricular de LE (PCLE) indica, em Santa Catarina, a aprendizagem de uma LE é parte integrante do processo educacional, devendo ela, como disciplina, estar em pé de igualdade com as outras no contexto escolar:

Até meados da década de 80 , a LE que predominava nas escolas públicas de Santa Catarina era o inglês. A partir dessa época, houve modificação na política de ensino de línguas, passando-se de uma posição monolinguística para uma posição plurilinguística nas escolas mais bem estruturadas, oferecendo-se francês, espanhol, alemão e italiano nos currículos escolares de $1^{\circ}$ e de $2^{\circ} \mathrm{grau}$ (SANTA CATARINA, 1998, p. 92).

Apesar da oferta de outras opções de $L E$, o inglês ainda era a língua que predominava nos currículos das escolas de ensino fundamental e médio nesse período. Em 2019, foi lançado o Currículo Base da Educação Infantil e do Ensino Fundamental do Território Catarinense (CBEIEFTC), em que é feita a seguinte ressalva quanto ao início do ensino da LI nos municípios: "[...] muitos municípios têm o início do percurso formativo dessa língua na Educação Infantil, ou nos anos iniciais do Ensino Fundamental" (SANTA CATARINA, 2019, p.297). Torna-se importante a citação desta ressalva, pois o município em estudo faz parte dos municípios do estado que a colocam em prática.

O município foco desta pesquisa é um dos municípios do estado de Santa Catarina que passaram a oferecer o ensino da Língua Inglesa para a Educação Infantil e para o Ensino Fundamental I a partir do ano de 2003. Apesar disso, essa oferta sofre alteração de governo para governo, sendo que em alguns o ensino da LI começa no Berçário e em outros somente na Pré-escola.

Quando começou a ser ofertada a $\mathrm{Ll}$, essas aulas eram ministradas pelos professores de sala, formados no antigo magistério (os com mais tempo de trabalho, 
correspondendo ao ensino médio) ou em Pedagogia. Esses professores recebiam capacitação periódica de uma empresa de Curitiba - PR para tornarem-se aptos a também lecionarem essa disciplina. A partir do ano de 2002, começaram a ser contratados professores formados em Letras com habilitação em Língua Inglesa e esses passaram a dar aula nos três níveis como acontece até hoje.

Esses profissionais podem ser efetivos na rede municipal de ensino, ou seja, terem feito concurso público e sido contratados ou podem ser contratados por tempo determinado de, no máximo, dois anos. Na cidade em questão, esses profissionais contratados são identificados como Admitido em Caráter Temporário (ACT). $O$ município, até o momento em que este estudo foi realizado (2020), ainda não possuía uma proposta curricular.

No PME (Plano Municipal de Educação) do município foco desta pesquisa, que foi elaborado entre 2013 e 2014, encontramos algumas metas e estratégias relativas à formação de professores. A meta 15 prevê a formação continuada, pois acredita que esta deve ocorrer de forma contínua e permanente, assim proporcionando "[...] um processo que confira ao docente conhecimentos, habilidades e atitudes para criar profissionais reflexivos" (IMBERNÓN, 2011, p. 58). Na estratégia 15.11, há a única informação específica para a formação de professores de "idiomas", que é:

Apoiar a instituição de Programas de concessão de bolsas de estudos para que os/as professores/as de idiomas das escolas públicas de Educação Básica realizem estudos de imersão e aperfeiçoamento nos países que tenham como idioma nativo as línguas que lecionem (RIO NEGRINHO, 2015, p. 40).

Nesse sentido, Fraga, Diamantino e Barreto (2016) escrevem que independente das qualificações dos professores de LE, outros fatores influenciam diretamente nos resultados do seu trabalho, dentre eles a falta de políticas mais consistentes. Os professores enfrentam desafios diários, como a grande quantidade de alunos por sala e a falta de estrutura física:

Dentre esses desafios destacamos o grande quantitativo de alunos no espaço da sala de aula e muitas vezes a estrutura física desfavorável para o ensino da LA. Não podemos atribuir a causa do fracasso do ensino de idiomas apenas à má formação dos profissionais, pois esse olhar micro e restrito não condiz com a realidade social e política que vivenciamos (FRAGA; DIAMANTINO; BARRETO, 2016, p. 320).

Quanto à realidade profissional dos professores de LE, Fraga, Diamantino e Barreto (2016) também lembram da crença da superioridade do professor estrangeiro, nativo da língua estrangeira, em relação ao professor não nativo, e citam o relatório da UNESCO (1953) que desmistifica isso e destaca que não basta ser falante nativo da língua para estar qualificado a ensiná-la.

Meneses (2017) ressalta que a relevância do ensino de LI aponta para a necessidade de se criar condições para que ele aconteça. Dentre o que é considerado 
FUERST, C. M.; KOERNER, R. M.

mais importante temos o aumento na carga horária semanal, menor número de alunos nas salas, contratação de mais professores e, o mais importante, "a parceria estreita entre a universidade e a escola na formação de docentes de inglês, pois, somente assim haverá efetivamente o aprendizado do idioma". (MENESES, 2017, p. 162).

\section{Percurso METOdológico}

A pesquisa que constitui este artigo foi realizada em uma rede pública de Educação de uma cidade de pequeno porte de Santa Catarina. As professoras participantes atuam no ensino da Língua Inglesa. Um dos passos nesse percurso foi a aprovação do projeto, mediante o Parecer de número 2.903 .340 no Comitê de Ética em Pesquisa.

A pesquisa que aqui se apresenta tem características de um estudo qualitativo, uma vez que pretende identificar as percepções de professoras acerca do ensino de Língua Inglesa no município. Buscam-se certas singularidades na fala dessas professoras: "A abordagem qualitativa defende uma visão holística dos fenômenos, isto é, que leve em conta todos os componentes de uma situação em suas interações e influências recíprocas" (GATTI; ANDRÉ, 2011, p. 30).

A coleta de dados foi realizada em duas etapas: através do envio de questionários, respondidos por todas as professoras de Língua Inglesa do município (um total de 13) e entrevista, realizada posteriormente com as quatro professoras efetivas dessa rede de ensino, entre as 7 que manifestaram interesse em continuar na pesquisa. As professoras que responderam ao questionário são nomeadas pelas letras de $\mathrm{A}$ a $\mathrm{M}$. Os quatro professores que participaram da entrevista são do sexo feminino, por isso passarão a ser tratadas como "as participantes" e serão identificadas, no decorrer da apresentação dos resultados, com nomes fictícios. Neste artigo trazemos excertos das entrevistas.

As profissionais que atuam no ensino da LI no município em estudo possuem formação inicial completa e/ou estão cursando Letras. Dos 13 participantes que responderam o questionário, três responderam que lecionam no EF I, 2 lecionam no EF II e 8 lecionam em ambos os níveis. Destes professores, somente 11 lecionam Língua Inglesa e 2 lecionam também português, pois possuem dupla habilitação, sendo que, quando fizeram o concurso, ainda era permitido fazê-lo para as duas áreas ao mesmo tempo, o que hoje não acontece mais - justificando a maioria atuar exclusivamente no ensino de LI. Cinco participantes atuam como professoras há até 5 anos, uma de 6 a 10 anos, seis entre 11 e 20 anos e uma já tem mais de 21 anos de atuação docente.

Os dados resultantes da aplicação do questionário aos professores, inicialmente, foram examinados considerando-se a frequência de determinadas respostas. Das respostas foram captadas regularidades e divergências, na tentativa de compreender suas práticas pedagógicas em suas aulas de Língua Inglesa.

OS PROFESSORES DE LÍNGUA INGLESA: INVESTIMENTO NA PRÓPRIA FORMAÇÃO E CONDIÇÕES DE TRABALHO

A questão sobre a formação foi feita na entrevista, indagando as professoras acerca de suas percepções quanto à formação continuada. Elisa e Fernanda destacam a 
experiência como a principal fonte de conhecimento e de preparação para o desenvolvimento do seu trabalho, apesar de ambas dizerem que a formação inicial foi importante. Porém, a professora Elisa vai além e nos chama a atenção quando declara ser muito importante buscar sempre, pois desde sua formação muita coisa mudou, inclusive os alunos estão muito antenados, o que não permite que o mesmo trabalho ou a mesma forma de trabalhar ainda perdure:

\begin{abstract}
Pela prática. Com certeza pela prática porque, na faculdade, a gente só tem a teoria, né, e, assim, nem é toda a teoria ainda que a gente necessita. Então é lá na sala de aula que a gente vai ter a prática, né, e buscar sempre... porque se você for trabalhar a vida toda da mesma maneira, você não vai ter os mesmos resultados, né, os resultados positivos sempre porque a clientela muda. De 12 anos atrás, quando eu me efetivei, pra hoje, com certeza os de hoje, eles estão muito antenados e você tem que tá à frente deles e buscando pra trazer, pra que seja curioso pra eles porque senão não chama a atenção, né?(Elisa).
\end{abstract}

diz:

Já a professora Gabriela divide sua resposta entre os dois tipos de formação e

Alguma coisa ainda trago da minha formação acadêmica, mas muita coisa eu trago da minha experiência, do que eu já fiz e não deu certo, do que eu fiz e deu certo. Daí, assim, eu vou montando as minhas aulas. (Gabriela).

O que essas professoras relatam encontra eco em Tardif e Lessard (2005), quando estes afirmam que se aprende o ofício de ensinar, ensinando, e isso fica bem claro quando Elisa enfatiza que chega despreparada na sala de aula e com a prática vai percebendo o que o aluno precisa e $o$ que se pode ou não fazer:

\footnotetext{
A formação, ela, claro, ensina muita coisa, né, a gente vem meio despreparada, mas o que o aluno precisa, o que você pode trabalhar, o que você não pode, você realmente vê com a prática. (Elisa) (Grifo das autoras).
}

Nota-se que é quase a mesma preocupação de Gabriela quando ela diz que é a partir da experiência do que fez e deu certo ou que não deu certo, que monta suas aulas.

Já a professora Fernanda nos traz a visão de que a prática e a busca por atividades diferentes são indispensáveis, que não se pode trabalhar sempre da mesma maneira, pois resultados positivos não serão alcançados por muito tempo se as mesmas práticas forem usadas muitas vezes, pois o público muda e o que é interessante hoje, deixa de sê-lo em pouco tempo.

Segundo Nóvoa (2000), todas as instituições responsáveis pela educação devem ser envolvidas nos processos de formação continuada do educador; porém as professoras entrevistadas declaram que não recebem formação continuada, nem em 
FUERST, C. M.; KOERNER, R. M.

serviço nem fora dele, há anos, e as últimas que receberam não eram específicas na área de atuação. Sendo assim, quando sentem alguma dificuldade e/ou necessidade procuram saná-las por conta própria.

Sobre o município não disponibilizar formação continuada, todas foram unânimes e o depoimento da professora Elisa representa o de todas:

[...] Formação continuada é importante, só que tem que ser cada um por si, né? Porque não temos nenhuma disponibilidade de cursos, assim, pra professores. Não temos faz muitos... [...] É. Pra área, faz muitos anos que não temos. (Elisa) (Grifo das autoras).

Carvalho (1999) considera que formar professores é trabalhar numa situação muito particular, em que o conhecimento que se domina tem de ser constantemente redimensionado e reelaborado em razão das mudanças que ocorrem na sociedade. É a consequência, em grande parte, dos avanços da ciência e da tecnologia, tendo em vista que o processo de formação não cessa, envolvendo sempre novos contingentes de professores.

Nos depoimentos das professoras entrevistadas, percebemos que elas têm consciência da importância da formação continuada e demonstram interesse em participar das formações, o que vem ao encontro do que relata Carvalho (1999). Nos últimos anos, entretanto, as últimas gestões que governaram o município não investiram mais em formação em serviço, e quando o fizeram não foi nada específico na área de atuação, como seria o desejado e o ideal, conforme pudemos depreender dos depoimentos das participantes.

Em seus relatos, as professoras apresentam seus anseios em desenvolver aulas mais atrativas, dinâmicas e até contextualizadas entre o mundo e o dia a dia dos alunos, com o intuito de mantê-los interessados. Para isso, essas profissionais fazem cursos em escola de idiomas: [...] eu já fiz o curso de inglês particular, né, em escola de idiomas [...]-(Fernanda); cursos através da internet, [...] mas as formações que eu faço, são todas pela internet, tá? São cursos online-(Denise); ou assistem a vídeos que trazem o conhecimento que estejam necessitando no momento, mas todas indicaram fazer algo, pois reconhecem a importância que isso tem para que permaneçam a par das mudanças cotidianas que acontecem na LI e com os próprios alunos.

As mudanças, em grande parte, ocorrem no âmbito das tecnologias e vêm ao encontro dos interesses dos alunos, pois, atualmente, não importa a idade, a maioria tem certo conhecimento sobre as tecnologias. A professora Denise relatou que todos os cursos que ela fez destacaram a importância de lecionar usando as novas tecnologias e os espaços diferenciados como estratégia para o aprendizado:

[...] todos os cursos falam sobre isso, tecnologia, os espaços diferenciados na sala de aula, você não trabalhar todos, assim, um atrás do outro, sabe, enfileirados. Sempre, assim, tentar fazer várias estratégias pra que eles aprendam. [...] (Denise) (Grifo das autoras).

Em seu relato, a professora Fernanda destaca que os alunos de hoje são muito antenados e que, para tornar as aulas interessantes, o professor deve estar à frente deles, 
trazendo algo que lhes aguce a curiosidade, que chame a atenção; sendo assim, a formação continuada, em serviço ou não, é de grande valia para suprir essas e outras necessidades que se apresentam cotidianamente.

No depoimento da professora Elisa, observamos que ela investiu ainda mais, pois, além dos cursos de idiomas e outros aqui no país, também fez uma viagem para o exterior onde fez curso de inglês:

\begin{abstract}
Eu sempre, né, quando eu posso ali, quando eu tenho condições, eu sempre procuro ir atrás e fazer um curso ou... nem que seja um curso curtinho, né, mas eu sempre procuro fazer e acho importante sim. Não podemos parar, né? Fiz. Fiz um curso em escola de idioma e fiz um curso fora também, um curso curtinho, né, fora do país. Um curso de aperfeiçoamento que eu acho que... apesar de ser curto, né, eu acho que valeu até pelo curso que eu fiz aqui porque foi $100 \%$ imersão, né? (Elisa) (Grifo das autoras).
\end{abstract}

Em seus depoimentos, as professoras reconhecem a importância de manteremse atualizadas e acreditam que para conseguirem mobilizar seus alunos e passar o conhecimento pretendido precisam diversificar suas práticas diárias.

Consideramos o interesse e a disponibilidade dessas professoras muito válidos, porém não podemos deixar de pensar nas professoras que, por algum motivo, não fazem essas formações. Com relação a isso, novamente se faz relevante lembrar que, se as formações fossem disponibilizadas pelo município, ou seja, em serviço, outras professoras, possivelmente, as fariam.

O não oferecimento dessa formação continuada vem de encontro às recomendações do que consta no Plano Municipal, em que há uma referência específica à formação de professores de "idiomas", que é:

\footnotetext{
Apoiar a instituição de Programas de concessão de bolsas de estudos para que os/as professores/as de idiomas das escolas públicas de Educação Básica realizem estudos de imersão e aperfeiçoamento nos países que tenham como idioma nativo as línguas que lecionem. (MUNICÍPIO, 2016, p. 40).
}

Conforme os relatos das professoras participantes desta pesquisa, percebemos que o município está deixando de cumprir suas metas no que se refere à formação continuada para professores de $\mathrm{LI}$ e, com isso, pode estar privando seus professores e seus alunos de obterem melhores resultados no aprendizado. Vale ressaltar, contudo, que as professoras não se condicionaram a essa situação e mostraram ter iniciativa para investirem em sua própria formação:

[...] quando eu preciso de algum curso, eu corro atrás, eu faço por conta própria daí. (Gabriela).

A oferta de formações continuadas faz parte das condições de trabalho do professor, já que elas interferem no fazer docente. O termo "condições de trabalho" dos 
FUERST, C. M.; KOERNER, R. M.

professores é discutido por muitos autores e possui muitas variáveis, porém destacaremos o que Tardif e Lessard (2009) trazem no livro O trabalho docente, em que descrevem dimensões quantitativas do ensino, como tempo de trabalho, quantidade de alunos por sala e salário. Esse conceito corrobora o de Oliveira e Assunção (2010), quando estes o definiram englobando tanto o processo de trabalho quanto as condições de emprego, formas de contratação, remuneração, carreira e estabilidade.

As condições de trabalho vivenciadas pelas professoras participantes da pesquisa foram depreendidas de respostas dadas a questionamentos sobre a questão do ensino. Foram sinalizações de que tais condições interferem no seu fazer docente. Ao analisarmos as respostas dadas na entrevista, percebemos que as quatro professoras fizeram declarações em tom de pesar com relação ao pouco número de aulas semanais e à falta de investimento na formação continuada, pois acreditam que isso afeta diretamente suas condições de trabalho. Condições estas que não são levadas em conta, independente dos governos que vão e vêm, como relata a professora Elisa ao falar sobre as formações continuadas que:

[...] quando muda, né, a gestão, acaba mudando as pessoas que organizam. Então não teve mais [...]. (Elisa).

Vasconcelos (2009) lembra que é fundamental que aconteça a valorização e a qualificação dos professores para que ocorra uma mudança na qualidade do ensino no Brasil. No entanto, para que isso aconteça, é imprescindível que se ofereçam melhores condições de trabalho a esses profissionais, pois assim conseguirão desenvolver seus conhecimentos específicos e suas competências adequadas à atividade pedagógica.

Consideramos, a partir das palavras de Vasconcelos (2009), que melhores condições de trabalho não se limitam à formação dos professores, mas acreditamos que outros elementos, como os materiais que são disponibilizados ou não para a execução do trabalho, bem como as condições dos alunos, de um modo geral, também interferem diretamente.

Na pergunta sobre quais recursos os participantes usam nas aulas de LI, os mais citados foram: livro didático, multimídia (tv, rádio, computadores, tablet, caixa de som, internet), dicionário, gibis, tirinhas, músicas, trechos de filmes, e também foram citados giz, caderno e caneta. Verificamos que os recursos citados pelos professores são os que a maioria dos profissionais da rede pública de ensino dispõe e utiliza nas suas aulas.

A professora Fernanda elenca alguns elementos sobre isso:

\begin{abstract}
[...] é diferente de alguns anos que eu trabalhei em escolas de bairros mais afastados onde a realidade dos alunos e das famílias era mais precária, aí sim eu tinha mais dificuldade. Não sei dizer o porquê, se eles tinham outras preocupações, né, e menos o estudo. Então, de repente, falta de dinheiro, de comida em casa, tudo isso eu acho que atribuía, né? Mas, hoje em dia, eu já não tenho isso. [...] [...] inclusive, relacionado à tarefa, material, tudo que a gente pede, assim, eles compram, se for necessário, eles trazem o que tiver que trazer, de casa. É um ou outro que não o fazem. E, nessas escolas que eu trabalhei há alguns anos atrás, era o contrário. Então tarefa, nem pensar em pedir ou outro tipo de material, que eles não traziam. [...] (Fernanda).
\end{abstract}


As palavras da professora Fernanda enfatizam as de Vasconcellos (2009) e vão além, nos dão a oportunidade de (re)pensar não só as condições de trabalho do professor, mas também as condições de "vida" do aluno, pois isso pode influenciar o desempenho escolar de ambos.

Também temos o relato da professora Gabriela, que nos informa que o município não possui material para as aulas de inglês na Educação Infantil e nem para as aulas do Ensino Fundamental I, então, para diversificar suas aulas, comprou uma coletânea de DVDs específica para este público:

\begin{abstract}
[...] eu trabalho com educação infantil, né, e ensino fundamental l. Então, pra eles, também é bem atrativo trabalhar com a música. Também trabalho... eu tenho, eu comprei uma coletânea que tem DVDs, sabe, e daí, ali, tem videozinhos que são bem fáceis pra eles entenderem, né? E daí eles assistem meus vídeos e já conseguem reconhecer o vocabulário, né, que a gente tá estudando. (Gabriela).
\end{abstract}

Nas palavras da professora, percebemos que o que nos diz Vasconcelos (2009) sobre as condições de trabalho dos professores dependerem de muitas coisas, uma delas, muito importante, é a disponibilidade de materiais que facilitem e tornem as aulas de inglês mais dinâmicas e atrativas. No caso da professora Gabriela, isso somente acontece porque a professora comprou seu próprio material.

Vasconcelos (2009) menciona que muitos docentes se sentem limitados pela falta de material e pela carência de recursos para adquiri-los, e, em razão disso, eles se submetem à rotina escolar, pois não acreditam mais em mudanças em seu trabalho.

As escolas do município possuem laboratório de informática, tablets (nos quais podem ser baixadas atividades específicas para serem realizadas na sala durante a aula), sala de vídeo ou Datashow (que pode ser levado na sala de aula), aparelho de som, cota de cópias para as atividades que precisam ser reproduzidas e acesso à internet.

Para fazer uso desses recursos, ao menos uma vez por semana, os professores precisam agendar com antecedência. Os recursos mais utilizados são o aparelho de som, para reproduzir músicas e áudio de textos, as cópias, em que constam a letra das músicas ou a transcrição do áudio, além do laboratório de informática e do Datashow, para a reprodução de vídeos e filmes, conforme as atividades planejadas.

Apesar de esses professores terem disponível, na medida do possível, esses recursos, estes não serão relevantes se não forem usados de maneira a promover ou facilitar o ensino e a aprendizagem da LI. Paiva (2015, p. 14) afirma que

é bem possível que o computador não chegue para todos, mas é preciso também ter em mente que nem o livro e nem o computador farão milagres no processo de aprendizagem. $\mathrm{O}$ sucesso da aquisição de uma língua estrangeira depende da inserção do aprendiz em atividades de prática social da linguagem e, dependendo do uso que se faz da tecnologia, estaremos apenas levando para a tela os velhos modelos presentes nos primeiros livros didáticos. 
FUERST, C. M.; KOERNER, R. M.

As palavras de Paiva (2015) nos levam mais uma vez a destacar a importância da formação continuada, citada na seção os professores de Ll: Investimento na própria formação, pois são nesses momentos que os professores aprendem a utilizar esses recursos, de modo a promoverem esta prática social.

Nos depoimentos das professoras entrevistadas, elas declaram que quando utilizam materiais diversificados e tecnologia em conjunto com materiais didáticos como livros e dicionários, conseguem melhor e maior participação dos alunos, assim como melhores resultados. Sobre isso, a professora Denise nos disse:

Então eles cobram uma coisa mais prática. Eles querem usar mais os computadores, que eles querem usar músicas, [...] não ficar mais na parte da matéria, da gramática, né, eles querem inglês mais na prática mesmo. (Denise).

A professora Gabriela comentou que usa o livro didático e nele há algumas atividades que sugerem o uso da tecnologia:

[...] a gente trabalha o livro didático, então ele traz ali algumas sugestões, que eles gostam bastante também é coisas mais relacionadas à tecnologia, tipo, mensagens de e-mail, [...] (Gabriela).

A professora Denise nos informou no questionário que quando trabalha com a escrita procura utilizar textos do cotidiano dos alunos, já que eles gostam muito de falar. Com essa informação, perguntamos se ela costumava desenvolver diálogos e ela nos respondeu que sim, pois como eles cobram o uso das tecnologias nas aulas de LI, uma das atividades que ela procura desenvolver, usando o computador, são os diálogos. Quando os alunos são levados ao laboratório de informática, lá fazem pesquisa e transcrevem os diálogos produzidos na sala de aula, da língua materna para a LI:

[...] eles querem, assim, mais na prática mesmo, que eles possam falar e se comunicar e que seja na prática. (Denise).

Algumas professoras disseram que usam recursos tecnológicos para assistir a vídeos e reproduzir músicas, sendo que a música foi citada pela maioria dos participantes da pesquisa na seção condições de trabalho. Apesar de essas professoras terem consciência da importância do uso das tecnologias digitais, percebemos que o uso ainda é feito de maneira esporádica e, quando acontece, tende a ser para suprir as necessidades da atividade que esteja sendo trabalhada. O uso dessas tecnologias é constatado no depoimento da professora Gabriela, quando ela nos relata que

Nós agora temos os tablets educacionais, né, que os alunos podem fazer pesquisas, podem ser instalados jogos também, né, dentro da língua inglesa, pra eles fazerem, jogarem. E nós também temos o laboratório de informática que nós podemos levar os nossos alunos. Só que é melhor trabalhar com eles em sala, com os tablets, que eu posso... eu proporciono um pra cada aluno porque na nossa sala de informática, ela já tá... ela... às vezes eu tenho que colocar 2, 3 alunos num computador só. Daí fica mais 
difícil pra eles trabalharem, pra eles entenderem como é que eles vão fazer as pesquisas. (Gabriela) (Grifo das autoras).

A professora Gabriela relata que usa tanto o laboratório de informática quanto os tablets, porém prioriza o uso dos tablets por ter a possibilidade de fornecer um para cada aluno e então poder trabalhar individualmente, diferente do que acontece quando usa computadores.

O Currículo Base da Educação Infantil e do Ensino Fundamental do Território Catarinense (CBEIEFTC) enfatiza a importância do uso das tecnologias digitais e nos traz a seguinte informação:

\begin{abstract}
Um aspecto marcante na formação do estudante é o seu interesse pelas tecnologias digitais e de comunicação que possibilitam a ampliação da visão cultural do aluno, além de proporcionar experiências significativas com a língua inglesa. (SANTA CATARINA, 2019, p. 299).
\end{abstract}

Nossos alunos "vivem" conectados e o interesse pelas tecnologias vem desde a tenra idade. Sendo assim, aliar-se a essas tecnologias e usá-las como instrumentos de ensino passa a ser de fundamental importância para que os alunos venham a ter contato com a Ll em uso.

\title{
CONSIDERAÇÕES FINAIS
}

Verificar quais são as percepções de professores sobre o ensino da LI em uma cidade de pequeno porte foi o objetivo aqui proposto. Para isso, foram enfocados aspectos como a formação docente, as condições de trabalho e os recursos disponíveis, a partir do que disseram professores, em resposta a um questionário e a uma entrevista semiestruturada. A questão que norteou a discussão dos dados aqui apresentados foi: Quais as percepções de professores sobre o ensino da LI em uma cidade de pequeno porte?

Quando analisamos os dados referentes à formação continuada dos professores, constatamos que eles, em razão da falta de oferta dessa formação em serviço e fora dele, têm procurado por conta própria fazer alguns cursos de forma a preencher a lacuna que, conforme esses profissionais, há anos vem sendo deixada de lado por seguidos governos.

Percebemos nos depoimentos das professoras que elas lamentam não receberem formação continuada, pois têm consciência de que essas formações poderiam ajudá-las no planejamento e no desenvolvimento de suas aulas, de maneira a atingir seus objetivos, como a participação e o aprendizado de seus alunos, além de conseguirem ampliar seus conhecimentos de como trabalhar diferenciadamente para identificar e ajudar os alunos com dificuldades no aprendizado da língua inglesa.

Concluímos também que, apesar de os dados mostrarem que as escolas onde lecionam os participantes disporem de recursos tecnológicos, algumas situações inviabilizam ou dificultam seu uso, sendo as mais citadas o deslocamento aos locais 
FUERST, C. M.; KOERNER, R. M.

onde são disponibilizados esses recursos ou mesmo a demora para instalá-los na sala de aula. As profissionais participantes afirmam que têm um planejamento a cumprir e que se "perderem" tempo com deslocamento e montagem/desmontagem dos aparelhos não conseguirão cumpri-lo.

A pesquisa revelou que o ensino da língua inglesa no município em estudo necessita de mais atenção e que algumas medidas devem ser tomadas de forma que os profissionais consigam desenvolver atividades significativas e tornar efetivo o ensino dessa língua.

Os dados mostram que o Ensino fundamental I não tem livro ou apostila disponível, ficando a cargo dos professores que lecionam para este nível, a partir do planejamento anual, buscar na internet ou em outro lugar atividades para copiar, quando há cota de cópias disponível, além de material de áudio e vídeo. Já os professores que lecionam para ao Ensino fundamental II têm disponível o livro didático, porém ele não contempla os mesmos assuntos que constam no planejamento anual, o que exige adequações constantes.

Essas informações nos levam ao questionamento de como um município, que há mais de 15 anos tem no seu currículo o ensino da língua inglesa no Ensino fundamental l, ainda não definiu essas questões.

A realização do trabalho dos professores, de forma geral, está sendo continuamente afetada e cerceada pelo contexto atual da educação e pelas dificuldades encontradas em seus locais de trabalho. Isso tudo pode estar contribuindo para uma constante baixa na qualidade do trabalho na área da educação.

Constantemente o professor é cobrado para que seja reflexivo, para que desenvolva o máximo de competências e para que questione suas práticas pedagógicas. Também são cobrados para que não desanimem, mesmo que tudo ao seu redor não conspire a seu favor. Cobram-lhe para que arrume tempo para continuar sendo "o melhor", apesar de ter que lecionar para inúmeras turmas, pois o número escasso de aulas em cada uma delas faz com que tenham que ter muitas turmas para "fechar" a carga horária.

Esse paradoxo precisa ser eliminado, mas, para isso é necessária a mobilização dos professores. Acreditamos que investimentos na educação, em especial na formação continuada, são extremamente necessários para o seu desenvolvimento profissional, pois ser reflexivo estando desestimulado e desatualizado não nos parece algo plenamente possível.

Apesar do tempo de experiência, o professor de LI precisa de amparo, que pode vir em formações em serviço ou apoio para que sejam feitas fora. O conhecimento que se pode adquirir nessas formações pode, dependendo de cada profissional, desenvolver, aperfeiçoar e trazer conhecimentos que poderão incrementar e facilitar suas aulas.

Artigo recebido em: 13/07/2020

Aprovado para publicação em: 03/11/2020

TEACHER'S PRECEPTIONS ABOUT TEACHING ENGLISH IN A SMALL CITY IN SANTA CATARINA STATE

ABSTRACT: This article will present some perceptions of teachers about the teaching of English with regard to teacher's training, working conditions and, pedagogical resources available to

Inter-Ação, Goiânia, v.45, n.3, p. 969-984, set./dez. 2020. Disponível em: <http://dx.doi.org/10.5216/ia.v45i3.64424>. 
them. It is a qualitative study. Questionnaires were answered by the English teachers of the city and an interview with four of these teachers was made. From the analysis it was possible to understand that there is an absence of specific continuous qualification for English teaching and for this reason, they look for alternatives to stay up to date. There is a perception that the time for the development of language skills is limited even there are available pedagogical resources. Regarding the use of textual genres, there is small spectrum of options, such as, lyrics, dialogs and games, indicating a tendency to ludic themes.

KEYWORDS: Teachers of English; teachers qualification; working conditions; use of textual genres.

PERCEPCIONES DE PROFESORES SOBRE EL ENSEÑO DE LA LENGUA INGLESA EN UNA PEQUEÑA CIUDAD DEL ESTADO DE SANTA CATARINA

RESUMEN: En este artículo serán presentadas percepciones de profesores sobre la Enseãnza del inglés con relación a la formación, a las condiciones de trabajo y a los recursos pedagógicos. Se refiere a una búsqueda cualitativa. En la recolección de datos usamos cuestionários respondidos por los profesores de inglés de la ciudad y entrevistas con cuatro profesoras. Desde la análise, fue possible entender que hay ausencia de formaciones continuadas y que, por eso, las profesoras buscan alternativas para se manteneren actualizadas. Hay la percepción de que hay poco tiempo para el desarrollo de las habilidades linguisticas, mismo que haya recursos pedagógicos disponibles. Con relación al uso de los géneros textuales, hay poca variación, se quedando entre letra de música, diálogo y juegos, indicando una tendencia al lúdico.

PALABRAS CLAVE: Profesores del idioma inglés; Formación Docente; Condiciones de Trabajo; Uso de Géneros textuales.

\section{REFERÊNCIAS}

BRASIL, Collecção das Leis do Imperio do Brasil de 1851.Tomo XII. Parte II. Rio de Janeiro: Typographia Nacional, 1851.

BRASIL. Parâmetros Curriculares de Língua Portuguesa. MEC, Brasília, 1998.

BRASIL. Lei de Diretrizes e Bases da Educação Nacional n. 9.394, de 20 de dezembro de 1996. Brasília, 1996.

BRASIL. Lei n 4.024, de 20 de dezembro de 1961. Fixa as diretrizes e bases da educação nacional. Lei de Diretrizes e Bases da Educação-LDB. Brasília, DF, 1961. http://wwwp.fc.unesp.br/ lizanata/LDB\%204024-61.pdf Acesso em: 20 fev. 2020.

CARVALHO, M. A.; ALONSO, M. R. M. H. Formação continuada de professores e mudança na prática pedagógica. In: ALONSO, M. (Org.). Prática docente: teoria e prática. São Paulo: Pioneira, 1999. 
FUERST, C. M.; KOERNER, R. M

CHAGAS, R.V.C. Didática especial de línguas modernas. São Paulo: Companhia Editora Nacional, 1967.

CHAVES, C. O ensino de inglês como língua estrangeira na educação infantil: para inglês ver ou para valer? 2004.26 p. Monografia (curso em Especialização em Educação Infantil) - Pontifícia Universidade Católica do Rio de Janeiro, 2004.

FRAGA, C. G. R.; DIAMANTINO. P. R.; BARRETO, D. A. B. A formação do professor de línguas adicionais $\mathrm{e}$ os saberes envolvidos nas práticas pedagógicas. Práxis Educacional, Vitória da Conquista, v. 12, n. 22 p. 315-336 - maio/ago. 2016.

GARCIA, E. F. O projeto pombalino de imposição da língua portuguesa aos índios e sua aplicação na América meridional. Tempo, Niterói, Vol. 12, n. 23. 2007;

GATTI, B.; ANDRÉ, M. A. D. A relevância dos métodos de pesquisa qualitativa em Educação no Brasil. In: WELLER, W.; PFAFF, N. (Org.). Metodologias da pesquisa qualitativa em educação: teoria e prática. Petrópolis: Vozes, 2010. p. 29-38.

IMBERNÓN, F. Formação continuada de professores. Porto Alegre: Artmed, 2011.

MENESES, D. A. Ensino de Inglês e Formação de Professores: Reflexões sobre o contexto Brasileiro. Rio de Janeiro. Rev. Eletrônica Pesquiseduca, v. 09, n. 17, p. 151-164. jan.-abr. 2017.

NÓVOA, A. Os professores e a história da sua vida. In: NÓVOA, A. (Org.). Vida de professores. Portugal: Porto, 2000a.

OLIVEIRA, D.A.; ASSUNÇÃO, A.A. Condições de trabalho docente. In: OLIVEIRA, D.A.; DUARTE, A.M.C.; VIEIRA, L.M.F. Dicionário: trabalho, profissão e condição docente. Belo Horizonte: UFMG/Faculdade de Educação, 2010. CDROM.

PAIVA, V.L.M.O. A LDB e a legislação vigente sobre o ensino e a formação de professor de língua inglesa. In: STEVENS, C.M.T; CUNHA, M. J. Caminhos e Colheitas: ensino e pesquisa na área de inglês no Brasil. Brasília: UnB, 2003. p.53 - 84

PAIVA, V.L.M.O. O uso da tecnologia no ensino de línguas estrangeiras: breve retrospectiva histórica. In: JESUS, D. M. de; MACIEL, R. F. (Orgs.). Olhares sobre tecnologias digitais: linguagens, ensino, formação e prática docente. Campinas, SP: Pontes Editores, 2015. p.21-34.

RIO NEGRINHO. Secretaria Municipal da Educação. Plano Municipal de Educação de Rio Negrinho - Lei no 2.743/2015.

SANTA CATARINA. Secretaria de Estado da Educação e do Desporto. Proposta Curricular de Santa Catarina: Educação Infantil, Ensino Fundamental e Médio: Disciplinas Curriculares. Florianópolis: COGEN, 1998.

Inter-Ação, Goiânia, v.45, n.3, p. 969-984, set./dez. 2020. Disponível em: <http://dx.doi.org/10.5216/ia.v45i3.64424>. 
SANTA CATARINA. Secretaria de Estado da Educação e do Desporto Versão final do Currículo Base da Educação Infantil e do Ensino Fundamental do Território Catarinense. Escrito por Sicília Vechi. Publicado: 19 julho 2019.

TARDIF, M; LESSARD, C. O trabalho docente: Elementos para uma teoria da docência como profissão de interações humanas. Rio de Janeiro: Vozes, 2005.

UNESCO. The Use of the Vernacular Languages in Education. Paris: Unesco, 1953. Disponível

em: http://www.tolerancia.org/upimages/Manifiestos/unesco_1953_english.pdf. Acesso em: 09 nov. 2020.

VASCONCELOS, M. L. M. C. A formação do professor do ensino superior. Niterói: Intertexto; São Paulo: Xamã, 2009.

\footnotetext{
Cremilda Martins Fuerst: Graduada em Letras Português Inglês pela Universidade do Contestado (2008) e em Letras Português Espanhol pela Universidade Estadual de Ponta Grossa (2015). Pós-graduada em Metodologias Inovadoras do Ensino de Línguas: Português Inglês pela Associação Catarinense de Ensino Faculdade Guilherme Guimbala (2008). Mestre em Educação na Universidade da Região de Joinville UNIVILLE (Joinville - SC).

Orcid: https://orcid.org/0000-0002-0792-1852

E-mail:cremilda40.F@gmail.com
}

\footnotetext{
Rosana Mara Koerner: Graduada em Letras e Pedagogia, com mestrado e doutorado em Linguística Aplicada à Língua Materna pela Universidade Estadual de Campinas UNICAMP. É professora nos cursos de Letras e Pedagogia e no Mestrado em Educação da Universidade da Região de Joinville - UNIVILLE, em Joinville, Santa Catarina. Orcid: https://orcid.org/0000-0001-6117-7537

E-mail: rosanamarakoerner@hotmail.com
}

Este periódico utiliza a licença Creative Commons Attribution 3.0, para periódicos de acesso aberto (Open Archives Iniciative - OAI). 